\title{
The Syntax and Semantics of Cantonese Particles in the Left Periphery
}

\author{
John C. Wakefield \\ Hong Kong Baptist University \\ Palacký University Olomouc
}

\begin{abstract}
Adopting the cartographic approach, this paper proposes syntactic positions for all left-periphery particles above the tense phrase (TP) in Cantonese. These include both sentence-final particles and sentence-initial particles that can be used in isolation as interjections. Based on previous syntactic proposals for the left periphery, a modification of Rizzi's (2001) split-complementizer phrase (Split-CP) structure is proposed. A Deictic Phrase (DeicP) is added above the finite phrase (FinP) for the Cantonese "tense" particles laa 3 and lei4(ge3). Then, based on a number of proposals inspired by Speas and Tenny (2003), two functional phrases are added above the force phrase (ForceP) - a higher affect phrase (AffectP) for Cantonese sentence-initial particles and a lower discourse phrase (DiscourseP) for most of the sentence-final particles. The resulting structure is tentatively proposed to account for the word order of all left-periphery particles in Cantonese, bringing the description of their syntax closer in line with a number of proposals based on left-periphery particles in other languages. This proposal includes a three-way distinction of the functions and meanings of left-periphery particles: 1) particles that lie between ForceP and TP do not refer directly to the discourse context; 2) particles that head DiscourseP do refer directly to the discourse; and 3) particles that head AffectP refer to the discourse and express human emotions.
\end{abstract}

\section{Keywords}

Cantonese, discourse particles, left periphery, syntax

Studies in Chinese Linguistics, Volume41, Number 2,2020, 109-138DOI: 10.2478/scl-2020-0004 (C) 2020 John C. Wakefield. Studies in Chinese Linguistics is published by Sciendo on behalf of T.T. Ng Chinese Language Research Centre, Institute of Chinese Studies, The Chinese University of Hong Kong. This work is licensed under the Creative Commons Attribution-NonCommercial-NoDerivatives 4.0 International License. 


\section{Introduction}

The term particle is used to categorize morphemes that do not readily fit into preexisting categories. One consequence of this practice is that morphemes with very different meanings, functions, and syntactic properties are given the same label. Cantonese has particles that occur in sentence-initial, sentence-medial, and sentence-final positions. The present paper only deals with those that are located in the left periphery, which is defined here as the collection of functional projections positioned hierarchically above the tense phrase (TP). A right-branching structure is adopted for the present analysis, so that all projections above TP are linearly to its left before any movement takes place, thus resulting in the term left periphery. Some particles in the left periphery appear in the sentence-final position because lower projections raise to the specifier (SPEC) of those particles' projections. Cantonese has an unusually large number of sentence-final particles (SFPs), with most linguists putting the number between 30 and $40 .{ }^{1}$ Among the left-periphery particles in Cantonese, SFPs are by far the largest subgroup.

Examples (1) through (6) illustrate most types of left-periphery particles discussed in this paper. These sentences are minimal pairs in the sense that each one includes the exact same TP; the only difference among the sentences is which particle(s), if any, are present.

(1) Keoi5 hai2 Waan1zai2 faan1 gung1. 3SG at Wanchai return work

'S/he works in Wanchai.'

(2) Haa2, keoi5 hai2 Waan1zai2 faan1 gung1 me1? SIP 3SG at Wanchai return work SFP 'What? S/he works in Wanchai?!'

(3) Keoi5 hai2 Waan1zai2 faan1 gung1 gwaa3. $3 \mathrm{SG}$ at Wanchai return work SFP 'I think maybe s/he works in Wanchai.'

(4) Keoi5 hai2 Waan1zai2 faan1 gung1 zaa3. 3SG at Wanchai return work SFP 'S/he only works in Wanchai.'

(5) Keoi5 hai2 Waan1zai2 faan1 gung1 wo5. 3SG at Wanchai return work SFP

'Someone said S/he works in Wanchai.'

1 The number can vary widely depending on how they are counted. Leung (2005 [1992]: 83), for example, put the number at close to 100 because he assumed that many SFPs had multiple meanings and counted each meaning as a separate particle. The particle laal was concluded to have seven meanings and was thus counted as seven SFPs. Tang (2020) included particles that he said headed a projection at the periphery of the little verb phrase (vP), and he therefore counted $>40$ SFPs. Here, I treat such particles as adverbs (cf. Matthews and Yip 2011: Ch. 18). 


$\begin{array}{lllllll}\text { Keoi5 hai2 Waan1zai2 faan1 gung1 } & \text { ge3 } & \text { laa3 } & \text { wo3. } \\ \text { 3SG at Wanchai return } & \text { work } & \text { SFP } & \text { SFP } & \text { SFP } \\ \text { 'Oh, so s/he works in Wanchai.' } & & & & \end{array}$

The fact that Example (1) is grammatical shows that SFPs are often an optional component of a sentence, but the English translations of Examples (1) through (6) illustrate that an SFP adds a specific meaning to a sentence. It is worth noting that sentences in some contexts will sound unnatural or overly abrupt if no SFP is used.

Examples (3) through (5) are all identical sentences except for the single SFP attached. On the surface, this appears to imply that SFPs are interchangeable. (Examples [2] and [6] could be added to this list of minimal pairs by removing the optional interjection from Example [2] and using any of the three SFPs in Example [6] on its own.) Most SFPs are not interchangeable in the same discourse context. For example, the sentence in Example (2) that uses the "surprise" question SFP mel must be used in a context where the contents of its proposition have just been revealed to the speaker, either verbally or pragmatically, and the speaker up to this point has believed a negative version of the proposition - in this case, that the person being referred to does not work in Wanchai. Example (3), which uses the SFP gwaa3 'I think/guess...', must follow a hearer's request for information about the proposition, and the speaker does not have a strong commitment about it, i.e., is not sure whether the person actually works in Wanchai. This demonstrates not only that SFPs' meanings differ from one another but also that they include speakers' stances and are linked to the surrounding discourse context in specific ways. This means that sentences like Examples (1) through (6) are minimal pairs at the sentence level only; they are not minimal pairs at the level of discourse, and accurate definitions of SFPs must account for this fact.

Example (2) demonstrates that a sentence-initial particle (SIP) can be used with an SFP, but only so long as the meanings of the two are compatible. Example (6) shows that SFPs can be used in clusters. The allowable ordering of SFPs within clusters provides a good source of evidence about their syntax (see Section 4).

The literature includes many studies on the syntax of the left periphery in a variety of languages, and it is not surprising that the numerous particles in the left periphery of Cantonese have been of great interest to linguists, who have made several proposals about their syntactic properties. After reviewing a number of proposals about the structure of the left periphery, I will then formulate my own proposal for the syntactic positions of all Cantonese leftperiphery particles.

Rizzi (1997) proposed a now well-known Split-Complementizer Phrase (Split-CP) Hypothesis based primarily on the leftward (i.e., upward) movement of focus and topic phrases in Italian. That structure was later refined (Rizzi 2001), 
and this more recent version of his proposed structure of the left periphery is adopted here as a starting point:

(7) Force $>$ (*Top) $>$ Inter $>$ (*Top) $>$ Foc $>$ (*Top) $>$ Fin $>$ TP

I adopt the notion of equating Force with clause type and assume that only clausetyping particles head the force phrase (ForceP). Some languages have overt clause-typing particles, and some linguists have analyzed Chinese SFPs as clausetypers (e.g., A. Law 2002, A. Law 2004 for Cantonese; Huang et al. 2009 for Mandarin), but such an analysis for Chinese is problematic because many SFPs can attach to more than one clause type (Li and Thompson 1981 for Mandarin; Sybesma and Li 2007 for Cantonese). (Examples [11] through [13] in Section 2.2 illustrate this for Cantonese.) This is true in many languages. Northern Veneto has an SFP mo that can attach to both imperatives and interrogatives, while the two particles po and $l u$ can be used with both interrogatives and exclamatives (Munaro 2010: 69). Many West Flemish discourse markers can also be used with more than one clause type, motivating Haegeman (2014: 126) to argue that these particles therefore are not in Force but rather select Force. She proposed that these particles head two speech act phrases (SAPs) above ForceP. Haegeman and Hill (2013) proposed the same analysis for Romanian particles. Inspired by Speas and Tenny's (2003) seminal paper that proposed two mood phrases at the top of the left periphery, many linguists have since proposed the existence of one or more functional phrases above ForceP.

Based on arguments from the literature, combined with the syntactic behavior and meanings of Cantonese particles, I will hypothesize that two functional phrases should be added above ForceP in Rizzi's structure, as shown in (8). In addition to accounting for the word order of Cantonese SFPs (see Section 4), I will explain how this structure is also motivated by their functions and meanings (see Section 5). The higher affect phrase (AffectP) is thus named because it is headed by particles that express speaker emotions, while the lower discourse phrase (DiscourseP) is headed by particles that refer to elements in the discourse context. In addition, a deictic phrase (DeicP) is added above the finite phrase (FinP), based on Sybesma's (1997, cited in Sybesma and Li 2007: 1778) argument that le, which is the Mandarin counterpart to Cantonese laa3, "performs a function similar to that of $\mathrm{T}$ in languages such as Dutch and English: by explicitly establishing a link with the speech moment, it anchors the sentence to the time axis of the real world". Smith (2007: 230), who also examined le, stated this idea as "The Deictic Principle", which states that "Situations - events and states - are temporarily located with respect to the present moment, Speech Time". Li and Thompson (1981) pointed out that $l e$ is not restricted to relating an event to the speech time; it can also relate the event to a past or future situation if this is explicitly stated in the sentence. In any case, it always relates an event to a specified time: past, present, or future.

The modified structure now looks like this, with the three additions to Rizzi's (2001) structure shown in bold: 
(8) Affect $>$ Discourse $>$ Force $>$ (*Top) $>$ Inter $>$ (*Top) $>$ Foc $>(*$ Top $)>$ Deic $>$ Fin $>$ TP

The paper proceeds as follows. The next section argues for a distinction between the two terms interrogative and question and further proposes that particles with the grammatical feature [+Inter(rogative)] head InterP, while those with the semantic feature $[+Q$ (uestion)] head DiscourseP based on the reasons that follow. Section 3 reviews the prior proposals for the syntax of Cantonese SFPs in relation to proposals that are based on other languages. This sets the stage for Section 4, which explains how the structure in (8) accounts for the word order of all Cantonese left-periphery particles. Section 5 discusses the difference in meanings between particles that lie above vs. those that lie below ForceP, as well as the difference in meanings between those that head DiscourseP vs. those that head AffectP, placing all the particles into three broad categories based on their meanings. The final section summarizes everything proposed in the paper.

\section{Interrogative particles vs. question particles}

The terms interrogative and question are frequently used interchangeably in the literature, even though they are recognized as being distinct notions. ${ }^{2}$ Not every interrogative is a question (e.g., "Why don't you get lost!"), and not every question is an interrogative (e.g., "You quit your job?!"). In light of this, the [+Q] feature is treated here as a semantic feature present in any morpheme that expresses the speech act of requesting information. The [+Inter] feature, in contrast, is treated strictly as a syntactic feature that types the clause as an interrogative (see Section 2.2 for details).

Syntacticians traditionally assumed that clause-typing particles were located at the head of CP (i.e., in C ${ }^{0}$ ), but after Rizzi's (1997) Split-CP Hypothesis was introduced, most syntacticians who adopt the cartographic framework now place clause-typers in Force ${ }^{0}$. One result of this is that both interrogative and question particles have been analyzed as occupying Force ${ }^{0}$ (or Inter ${ }^{0}$ ), based on the assumption that they have a [+Q] feature that types the clause as an interrogative. ${ }^{3}$ A. Law $(2002,2004)$ and Sybesma and Li (2007), for instance, referred to the SFPs maa3, mel, and aa4 interchangeably as "interrogative

2 Linguists who distinguish between the two often use them interchangeably for convenience. Obenauer (2006: 248, footnote 1) said, "Following common practice, I use the terms 'interrogatives' and 'questions' interchangeably, despite their not being synonymous".

3 It gets more complicated with $W h$-questions. Traditionally, $W h$-phrases were assumed to have a [+Inter] (normally called [+Q]) feature, but Aboh and Pfau (2010) argued that Wh-phrases do not mark the clause as interrogative, and that they move to SPEC of the focus phrase (FocP). They assumed interrogatives to be marked by a particle heading InterP. Somewhat related to this, Poletto and Pollock (2000) and Munaro and Pollock (2005) proposed that Wh-phrases move to SPEC of one of two Operator phrases in the left periphery. They assumed interrogatives to be marked in ForceP but noted that their analysis added two phrases to the left periphery. 
particles" and "question particles" and placed them all at the head of ForceP. Kuong (2008) does the same for maa3, mel, and a question particle mo4 that is used in Macau Cantonese. Among these particles, the status of maa3 is the least clear. In Section 2.1, I discuss how maa3 might be analyzed either as an interrogative particle or as a question particle, and I argue that it should be considered a question particle.

\subsection{The particle maa3}

Matthews and Yip (2011: 359) said that Cantonese "has no general-purpose question counterpart to Mandarin ma (maa3 is used in the greeting Lei5 hou 2 maa3 'How are you' but is relatively formal in Cantonese)". It is used "between strangers, for example at the first encounter and acquaintances rather than friends or family (p. 438)". This implies that maa3 is not a neutral clause-typing marker; otherwise, its use would not be context based. Contrary to this, Li (2006) argued that maa3 is actually an A-not-A construction, which is how neutral polar interrogatives are formed in Cantonese. This claim was based on evidence from Cheung (2001, cited in Li 2006: 158), which points out that A-not-A constructions in contemporary Cantonese are only of the type V-not-VP, but in the past, these used to also be of the type VP-not-V or VP-not, where the negation marker appeared at the end of the entire verb phrase and may or may not be followed by a repetition of the verb. When the verb was not repeated, then the negation marker $m 4$ appeared sentencefinally, and it would often be immediately followed by the SFP aa3, which is frequently used in A-not-A sentences. As such, $m 4+a a 3$ became maa3. Consider this historical example:

Keoi5 soeng2 cung4 loeng4 m4 ni?
3SG want follow good NEG SFP
'Does she want to get out (of prostitution) by getting married?'
(Wisner 1927: 278 , cited in Li 2006: 158 )

The A-not-A sentence in Example (9) takes the form VP-not. The negator $m 4$ follows the VP soeng2 cung4 loeng4, and the verb soeng2 is not repeated. The result is that $m 4$ and the SFP $n i$ appear together. If the SFP aa3 had been used, then this would give us the $m 4+a a 3$ combination. Other authors have also assumed that maa3 is made up of $m 4+a a 3$ (e.g., Kwok 1984; Leung 2005 [1992]). One reviewer rightly pointed out that, regardless of maa3's historical origin, it is very unlikely that current speakers represent maa3 this way in their mental grammars. This is a good point, because if they did, then there is no reason that a VP-final $m 4$ could not be used without aa3, which is optional in A-not-A questions, or why it cannot be used with other A-not-A-compatible SFPs, as illustrated with the now-outdated SFP in Example (9). Based on this, I will assume that maa3 is a single morpheme that has grammaticalized into its current form and further assume that it is not a [+Inter] particle that forms neutral, unbiased questions; it is instead a [+Q] question particle. There are five reasons behind this conclusion, the first three of which are based on usage and speaker intuition, and the other two 
of which are based on syntax: (1) questions formed by maa3 do not always sound natural to speakers (Sybesma and Li 2007: 1757, footnote 23); (2) some linguists do not think maa3 forms neutral polar interrogatives (p.c. Lisa Cheng, October 2019); (3) the use of maa3 is highly restricted to certain contexts (Matthews and Yip 2011); (4) it cannot be used in embedded clauses, indicating that it should be categorized among those types of discourse-related SFPs that never appear in embedded clauses, rather than as a marker of clause type; and (5) it cannot be used in combination with a question particle like nel that is compatible with A-not-A interrogatives. ${ }^{4}$

If $m a a 3$ is assumed to be a question particle, then the only means of forming interrogatives in Cantonese is with the A-not-A construction, an example of which is shown here.

$$
\begin{array}{ll}
\text { Lei5 heoi3-m4-heoi3 } & \text { (aa3)? } \\
\text { 2SG go-NEG-go } & \text { SFP } \\
\text { 'Are you going?' } &
\end{array}
$$

The V-not-V structure heoi3-m4-heoi3 is what marks the clause as an interrogative. The SFP aa3 is optional and cannot form an interrogative on its own; therefore, $a a 3$ is not what is typing the clause in (10). Arguably, the only function of $a a 3$ is to provide a voiced segment to enable the speaker to add a form of intonation that expresses connotative meaning. This could be why the meaning of aa3, as well as its Mandarin counterpart $a$, is so hard to pin down (cf. Simpson 2014): it is a host for parasitic tones of various meanings (see Wakefield 2020 for a detailed discussion of discourse tones).

Proposals for the syntax of A-not-A constructions were given by Huang et al. (2009: 254-255) and P. Law (2006: 99). Huang et al. argued that A-not-A interrogatives involve an interrogative functional head made up of the feature [+A-not-A], which is located where negation would appear in a negative sentence, and "the A-not-A constituent moves to an appropriate position in CP at LF". P. Law (2006) offered a similar proposal that involves "an abstract feature [+Q]" that is base generated adjoining to VP and raises to SPEC of CP in LF. Slightly modifying these ideas, I propose a null [+Inter] functional head associated with the A-not-A constituent; it heads a functional phrase adjoined to VP (i.e., where NegP would be located in a negative sentence) and raises from there to Inter $^{0}$ in LF. Another alternative would be to assume a null [+Inter] particle that is base generated in Inter $^{0}$ and undergoes long-distance Agree with the [+A-not-A] feature (cf. Aboh and Pfau 2010: 99).

4 Replacing the A-not-A structure in Example (13a) with maa3 results in an ungrammatical sentence:

*Keoi5 soeng2 heoi3 maa3 ne1?

3SG want go SFP SFP

'Does s/he want to go? (I wonder)' [maa3 and nel are in complementary distribution] 


\subsection{Question particles}

Cantonese has several [+Q] particles, which include the following: aa4, which requests positive or negative confirmation of the proposition $p$ (Wakefield2014); mel, which also requests such confirmation but additionally expresses a prior belief in the negative form of $p$ (Wakefield 2014); ho2, which elicits positive confirmation of $p$ (Chor et al. 2016); nel, which ponderingly questions $p$ and requests information about it; and ge2, which has been said to ask a "why" question (Fung 2000) and to express that $p$ is contrary to the speaker's expectation (Iida 2017). As already noted, the feature $[+\mathrm{Q}]$ is used differently here than the way it is typically used in the literature; it does not type the clause. Typing the clause as an interrogative is reserved for the $[+$ Inter] feature. The $[+\mathrm{Q}]$ feature is treated here as a semantic feature that indicates that the sentence is a request for information. Because the [+Q] feature does not type the clause, it is compatible with both declaratives and interrogatives. ${ }^{5}$ Nevertheless, for some reason, only certain $[+\mathrm{Q}]$ particles can be used on both types of clauses; the context must of course be suitable for a given particle to be used, but some [+Q] particles do not appear compatible with interrogatives in any context; so, in those cases, there must be something more than merely the context that prevents them from being used with interrogatives. In spite of this, the fact that some $[+Q]$ particles can be used with interrogatives shows that these two features (i.e., [+Q] and [+Inter]) do not exist in complementary distribution. Consider the examples in (11) and (12), which contrast the two question particles $m e l$ and $g e 2$ :
a. Lei1dou6 mou5 jan4 me1? here NEG person ME
'There's nobody here?'
b. *Dim2gaai2 lei1dou6 mou5 jan4 me1? why here NEG person ME
'Why is nobody here?'
a. Lei1dou6 mou5 jan4 ge2? here NEG person GE 'There's nobody here?'
b. Dim2gaai2 leildou6 mou5 jan4 ge2? why here NEG person GE 'Why is nobody here?'

Both $m e 1$ and ge 2 cause a declarative clause to be interpreted as a question, as illustrated in (11a) and (12a), but they contrast in their ability to attach to an interrogative, as shown in (11b) vs. (12b). The examples in (13a-b) show that

5 A reviewer pointed out that this is in line with traditional grammar descriptions that treat interrogative as a mood that is independent of a request for information. This is why echo questions, which request information, do not need to be interrogatives: "You're going to the party when?" 
the [+Q] SFP nel can also be used with either an interrogative, as in (13a), or a declarative that contains an embedded interrogative, as in (13b).
a. Keoi5 soeng2-m4-soeng2 heoi3 ne1?
3SG want-NEG-want go NE
'Does s/he want to go? (I wonder)'
b. M4-zi1 keoi5 soeng2-m4-soeng2 heoi3 ne1?
NEG-know s/he want-NEG-want go NE
'I wonder if she wants to go?'

Note that the English translation of (13b) uses 'I wonder' as a translation of "M4zil..." (lit.: '[I] don't know'). If the particle nel, which ponderingly questions $p$, were removed, then the sentence would translate best using the literal translation '(I) don't know if she wants to go', which is a statement rather than a request for information. This demonstrates that nel always forms a question, but that it can attach to either a declarative or an interrogative, demonstrating that it does not type the clause.

In addition to the above facts, there is another reason to assume that Cantonese question SFPs do not form interrogatives: there is evidence that they are analogous to rising-intonation questions, which are not interrogatives. Crosslinguistic evidence presented in Wakefield $(2014,2020)$ shows that rising tones in English are equivalent in function and meaning to the question particles me1 and aa4. Related to this, Kwok (1984) said that these two question particles form questions that are different from semantically neutral questions like those formed using maa3 in Cantonese (according to her) and using subject-auxiliary inversion (SAI) in English. She concluded that me1- and aa4-suffixed questions are not semantically neutral but are instead like intonation questions that imply that the speaker holds a particular belief about the proposition. Bailey (2010) similarly said that English can form questions either with SAI or with intonation, but that the pragmatics of each is different. Probably the most detailed study of risingtone questions comes from Gunlogson (2003), who referred to English intonation questions as "rising declaratives" (i.e., not interrogatives) and explained that they include presuppositions. Using numerous examples, Gunlogson demonstrated that rising declaratives do not share the same discourse-context distributions with interrogatives formed by SAI. She proposed the following generalization to explain the linguistic facts:

Declaratives [rising or falling] express a bias that is absent with the use of interrogatives; they cannot be used as neutral questions.

(Gunlogson 2003: 99).

Gunlogson (2003: 54) observed that rising declaratives "cannot readily be used as questions 'out of the blue,' with no particular context, as interrogatives can be". She illustrated this with the example shown in (14), where the question mark at the end of the clause in (14b) represents a rising tone on a declarative clause. 
(14) [context: initiating a phone conversation]

a. Is Laura there?

b. ??Laura's there?

c. ??Laura's there.

(Gunlogson 2003: 55)

In the discourse context of (14), the rising declarative question in (14b) pairs with the neutrally intoned declarative in (14c) because they both express a bias, i.e., both include a presupposition that prevents them from being used to initiate a conversation. This indicates that (14b) is a declarative rather than an interrogative. If this dialogue is translated into Cantonese, the question SFPs mel and aa 4 would both behave like the rising tone of (14b) - neither a mel- nor an aa3-suffixed sentence could acceptably replace the English sentence in (14b), and these Cantonese sentences would both pair with a neutrally intoned declarative "Laura hai2dou6" 'Laura's there' used in place of the English sentence in (14c). An A-not-A sentence, on the other hand, could form an unbiased polar question that would be acceptable in this context as a replacement for the English sentence in (14a): "Laura hai2-m4hai2dou6 aa3?" (Laura at-NEG-at there AA; 'Is Laura there?').

The following examples from Hirst (1983: 176) offer further evidence that rising questions are not interrogatives.

(15) a. Did he buy something?

b. Did he buy anything?

(16) a. He bought something.

b. *He bought anything.

(17) a. He bought something?

b. *He bought anything?

The question marks in $(17 \mathrm{a}-\mathrm{b})$ represent rising intonation. Hirst said that the two ungrammatical sentences (16b) and (17b) pair together as unacceptable sentences because the rising intonation of (17a) and (17b) does not change those declarative sentences into interrogatives. The unacceptability of sentences like (14b) and (17b) counters Allan's (2006: 7) claim that sentence pairs such as (18a) and (18b) "are uncontroversially formally distinct clause-types".

(18) a. John's gone to New York.

b. John's gone to New York?

We cannot say that sentences like (18a) and (18b) are "uncontroversially" distinct clause types because, as shown above, some linguists have argued otherwise based on convincing evidence. Allan supported his claim about (18a-b) by giving examples where intonation is used to mark clause types, such as in "Navajo [where] the imperative has the same morphosyntax as the declarative, but it is prosodically distinct" (Allan 2006: 7). Another example comes from Gungbe, a West African Gbe language, which uses a low tone to mark interrogatives 
(Aboh and Pfau 2010). It is true that prosody can be used to mark clause types, as it does in Navajo, Gungbe, and other languages, but this does not mean that the rising tone in (18b) must therefore necessarily have this function rather than a speech act function. Following the arguments put forth by Hirst (1983) and Gunlogson (2003), I conclude that (18a) and (18b) are both declarative clauses; the intonation of (18b) is a $[+\mathrm{Q}]$ discourse tone with semantic content - it is not a clause-typer. Simply put, the rising tones of (14b), (17b), and (18b) function to change a statement into a question, but do not change a declarative into an interrogative.

If English rising question tones do not type the clause, then by logical extension, the findings of Wakefield $(2014,2020)$ indicate that mel and aa4 are also not clause-typers. This research elicited consistent translations from native bilinguals, who rendered $m e l$ - and $a a 4$-suffixed sentences as rising declaratives in English. Based on this evidence, it was argued that $m e l$ and $a a 4$ are both equivalent (or very similar) in function and meaning to English's high-rising and mid-rising question tones, respectively, which attach to declarative clauses. The question SFPs mel and aa4 are thus construed as expressing biased questions (cf. Kwok 1984) without changing declaratives into interrogatives. Biased question particles are speech act particles that express notions related to evidentiality and speaker stance. They are assumed to occupy an SAP along with the majority of Cantonese SFPs. And since "[m]any SFPs can occur in declaratives as well as interrogative sentences" (Sybesma and Li 2007: 1743), they are assumed, à la Haegeman (2014), to lie above ForceP. ${ }^{6}$

Summarizing the discussion thus far, Cantonese has a null [+Inter] particle associated with A-not-A questions. The particle maa3 is assumed to be a [+Q] question-forming SFP, along with other [+Q] SFPs, such as aa4, mel, ho2, ge2, nel, etc., all of which express inherently biased questions but do not type the clause. These $[+\mathrm{Q}]$ particles are all assumed to occupy DiscourseP, along with the vast majority of Cantonese SFPs. The positions of all Cantonese SFPs are proposed in the next section.

\section{Cantonese SFPs}

In earlier work, most Cantonese SFPs were placed in $C^{0}$ (e.g., S-P Law 1990; Tang 1998), but at least one additional syntactic position had to be proposed because two or more SFPs often occur in sequence. To account for this, Tang (1998: 41-74) referred to three "inner particles", which he later expanded to a list of 10 (Tang 2002). He argued that these inner particles are an overt expression of tense and placed them in $\mathrm{T}^{0}$. The remaining SFPs were referred to as "outer particles" and placed in $\mathrm{C}^{0}$. Adopting Rizzi's Split-CP Hypothesis, A. Law $(2002,2004)$ placed

6 Related to this, Tang (2006) claimed that the well-documented rising question tone in Cantonese is an SFP that occupies the same syntactic position as mel. 
the inner particles ${ }^{7}$ at the head of a phrase she called $\mathrm{SFP}_{2}$, which she placed directly above the Focus phrase (FocP), and she placed outer particles in ForceP based on her assumption that all outer SFPs are clause-typers having the feature $[ \pm Q]$. She argued that what she referred to as the question particles (i.e., mel, aa4, and maa3) are [+Q] and that all the remaining outer particles are [-Q] because they type the clause as something other than an interrogative. Huang et al. (2009) similarly argued that all Mandarin SFPs are clause-typers, but as already pointed out, this is problematic since Mandarin SFPs can attach to more than one type of clause (e.g., Li and Thompson 1981; Li 2006). ${ }^{8}$ This is also true of Cantonese SFPs (e.g., Sybesma and Li 2007).

It is widely accepted that SFPs do not occur in embedded clauses (e.g., Tang 1998 for Cantonese; Munaro 2010 for Northern Veneto; Haegeman and Hill 2013 for West Flemish). Huang et al. (2009: 35) said that "[w] why [SFPs, which they referred to as clause-typers] in Chinese never occur with embedded clauses. Possibly, there are unidentified discourse functions that ma, $b a$, and ne perform that are associated only with matrix clauses". If Chinese SFPs are located in functional phrases above ForceP, and if these phrases do not project in embedded clauses, then this would account for why SFPs do not appear in embedded clauses. Related to this, Tang (2010: 61) separated SFPs that express mood from clause-typers by stating as follows: ${ }^{9}$

Mood and clause type are not the same. The former mainly expresses discourse meanings, and is related to the discourse context at the time of speech; the latter is classified according to sentence-internal meanings, and is determined by the grammatical properties of the sentence independent of the context (translation mine).

In line with this distinction, more recent work has located Cantonese SFPs at the head of one or more functional phrases above ForceP, and the same is true of discourse particles in other languages. This research program was initiated by Speas and Tenny (2003), who, based on particles in several languages, proposed two functional phrases above ForceP: ${ }^{10}$ a higher evaluation phrase (EvalP) and a lower

7 Note that A. Law's $(2002,2004)$ inner particles included zaa3, timl, and laa3, while Tang's (1998) inner particles included zaa3, lei4, and laa3. Tang suggested that zaa3 had various inflected forms that marked the force of the sentence (i.e., zaa3 declarative; zaa4 interrogative; ze $[\mathrm{k}] 1$ imperative), which would be an argument for placing them at the head of ForceP in Rizzi's SplitCP. Tang (2002) later listed the following as inner particles, or what he referred to there as "type 1 SFPs": laa3, laa1, lo1, lei4, zaa3, ze1, ge3, gaa3, lei4gaa3, and lei4ge3.

8 See Del Gobbo et al. (2015) for further arguments as to why Mandarin SFPs are not clause-typers.

9 Many linguists use the term "mood" in a way that equates it with "clause-type". Here, it is used in the same sense as "modality", which expresses speaker intent, beliefs, stance, and so on, and in line with this, many authors have referred to discourse particles as "modal particles" (e.g., Arndt 1960).

10 As far as I can tell, they did not explicitly state that the phrases are above ForceP, so they could have thought of them as lying at the top of a Split-ForceP structure. 
evidential phrase (EvidP). The following functional projections have since been proposed by other linguists to lie above ForceP: a single AttitudeP for Mandarin SFPs (Paul 2014); a higher speaker-oriented SAP and a lower listener-oriented SAP for Romanian and West Flemish discourse markers (Haegeman and Hill 2013; Haegeman 2014); and two epistemic phrases for Cantonese SFPs (Li 2006; Sybesma and Li 2007). Heim et al. (2016) proposed a higher call-on-addressee phrase and a lower speaker-commitment phrase, both of which were proposed to be phrases inside a Split-ForceP - this was based on discourse particles in English, Cantonese, and Medumba. Tang (2015) adopted Speas' (2004) proposal of four functional phrases having the following hierarchy: SA $>$ Eval $>$ Evid $>$ Epis. Tang (2015) then placed four Cantonese SFPs in three of these phrases based on their functions: "hearsay" wo5 and "interrogative" waa2 in SAP; "unexpectedness" wo4 in EvidP; and "obviousness" lo1 in EpisP. In the structure shown in (8), I propose a higher AffectP and a lower DiscourseP, and I further hypothesize that these two phrases above ForceP do not project in embedded clauses, which is why they only appear in main clauses. ${ }^{11}$

Tang's (1998) earlier work on Cantonese SFPs that placed most SFPs in $\mathrm{C}^{0}$ was comprehensive in the sense that it proposed syntactic positions for the entire set of SFPs. Sybesma and Li's (2007) study is likewise a comprehensive treatment, but it adopted the cartographic approach. Their study broke all Cantonese SFPs down into what they called minimal meaning units (MMUs). The onset, rime, coda, and tone of an SFP are treated essentially as morphemes that head their own functional phrases. Out of the 15 phonemes and tones that are used in SFPs, 11 were treated as MMUs. The four phonemes and tones that are not treated as MMUs merely have a phonological function. The resulting structure that Sybesma and Li proposed is as follows:

(19) Epist $_{1}>$ Epist $_{2}>$ Force $>\operatorname{Mood}_{\text {Evid }}>\operatorname{Mood}_{\text {Eval }}>\operatorname{Mood}_{\text {Inf }}>$ Discourse $>$ Foc $>$ Deic $>$ Fin $>$ TP

In a roll-up fashion, the MMUs that head lower phrases raise to the SPEC positions of higher phrases, which results in the correct ordering of an SFP's MMUs. For example, in order to form "obvious" $l o l$, the DeicP that is headed by $l$-raises to the SPEC of $\operatorname{Mood}_{\text {Inf }} \mathrm{P}$, which is headed by $-o$, and then $\operatorname{Mood}_{\text {Inf }} \mathrm{P}$ raises to the SPEC of Epist $\mathrm{P}$, which is headed by tone 1. Impressively, this accounts for the phonological forms of most SFPs, and even for many SFP clusters such as ge3 le3 wo3 shown in Example (6), which involves only three phrases according to Sybesma and Li's account: the FinP headed by $g$-; the DeicP headed by $l$-; and the $\operatorname{Mood}_{\text {Inf }} \mathrm{P}$ headed

11 Alternatively, one could propose that an AffectP and a DiscourseP project in both main and embedded clauses, but that they only host particles in main clauses. Haegeman (1997: 54) said that on the principle of economy, it would be preferable that structures only include projections containing grammatical material, but that one could also adopt a view where structures always include specialized projections even when they are empty. 
by $-o$. The rime $-e$ and tone 3 are default forms with no meaning, and the initial $w$ - is also used in this case for strictly phonological reasons.

Sybesma and Li (2007) offer an impressive and very informative general description of the set of Cantonese SFPs, but their proposal is not without problems. For example, they list seven SFPs whose segments do not fit onto their structure, even though their structure is an attempt to account for all SFPs (p. 1740, footnote 5); it is unclear how those seven SFPs might fit into their proposal. Unless there is strong reason to adopt their relatively more complex structure, it seems reasonable to assume a simpler explanation for the similarity in meanings and functions observed among Cantonese SFPs that have the same onset (or both onset and rime), namely that it could be due to their having grammaticalized from the same words rather than because the onsets and rimes themselves have meanings.

If we adopt the structure in (8), and further assume that the majority of SFPs head a single functional phrase - as was proposed in earlier works (S.-P. Law 1990; Tang 1998, Tang 2002; A. Law 2002, A. Law 2004), then it appears possible to propose syntactic locations for all Cantonese particles in the left periphery and account for all the acceptable order of particles in clusters. This analysis of the syntax of Cantonese particles aligns more closely with proposals made for the left periphery of other languages, as explained in the following section. If this is on the right track, it arguably brings us a step closer to a description of the left periphery that applies universally.

\section{Proposing locations for all Cantonese left-periphery particles}

The inclusion of two phrases above ForceP as shown in (8) is motivated by a number of studies, beginning with the seminal one by Speas and Tenny (2003). There is a difference in the types of particles located in these two phrases, and this difference has been described broadly in terms of whether the function of the particle heading the phrase is speaker-oriented or hearer-oriented. Speas and Tenny (2003: 320) thought of the speech act layer as a ditransitive structure, saying "we may think of the speaker as the agent of the speech act, the utterance content as its theme, and the hearer as its goal". They placed a speaker-oriented SAP at the top of the structure, which they later called an evaluation phrase. Haegeman (2014: 135) agreed with this ordering, placing a speaker-oriented SAP at the top of her structure, saying that this phrase "relates the utterance to an addressee as the one for whom the utterance is intended". It is easy to see how this relates to the speaker's role of agent (cf. Speas and Tenny 2003) and, therefore, why Haegeman referred to this phrase as speaker-oriented. Which particles head the higher of these two phrases, and which head the lower, can be determined by their syntactic order, but the distinction between these two groups of particles must be described in terms of their functions and meanings. However, the abstract nature of the particles' meanings makes it difficult to pin down the difference between these two groups of discourse particles. It is therefore not surprising that Heim et al. (2016: 125) had an "analysis [that] differs from previous ones in 
that it locates the argument representing [addressee] higher than that representing [speaker]" (i.e., the reverse of Speas and Tenny). After explaining my proposal for the positions of all particles in the left periphery of Cantonese, the following section then hypothesizes a way of classifying all left-periphery particles into three groups: those that appear between ForceP and TP, those that head the lower of the two phrases above ForceP, and those that head the higher phrase above ForceP. My proposed structure in (8), is repeated here as ( $8^{\prime}$ ) for convenience, and excludes all of the optional Topic phrases, which are not relevant to the discussion.

(8') Affect $>$ Discourse $>$ Force $>$ Inter $>$ Foc $>$ Deic $>$ Fin $>$ TP

Working from the bottom upward, I will explain how all the Cantonese leftperiphery particles are hypothesized to fit into this structure:

(20)

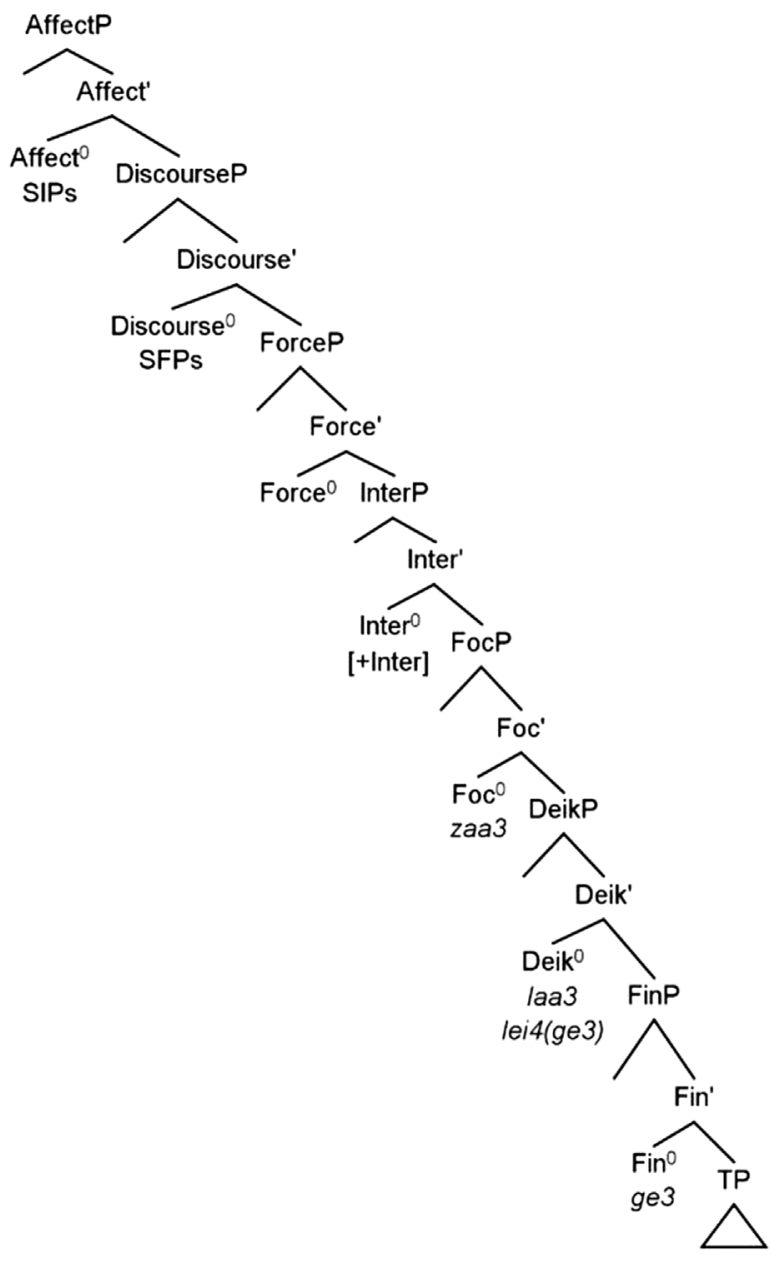


When functional phrases are headed by a particle, lower phrases raise up in a rollup fashion to the SPEC positions of higher phrases, resulting in a sentence-final order for all of the particles, with the higher particles appearing linearly to the right of lower particles (cf. Sybesma and Li 2007; Munaro 2010; Haegeman and Hill 2013). The only particles that do not attract a lower phrase to raise to its SPEC position are SIPs, and they therefore always appear in the sentence-initial position. The order of the SFP cluster ge3 laa3 wo3, as shown in Example (21), for instance, is due to FinP raising to the SPEC of DeicP, and then ForceP raising to the SPEC of DiscourseP. An SIP could optionally be added at the head of AffectP.

There are so many SFPs in Cantonese that it is impractical to list and describe them all here. Readers can refer to other authors' attempts to describe them all, such as Kwok (1984), Leung (2005 [1992]), Sybesma and Li (2007), and Matthews and Yip (2011). Nevertheless, syntactic positions will be proposed for all the SFPs by referring collectively to each subgroup that heads a particular phrase and proposing the shared semantic features for each subgroup.

Two particles that head the lowest two phrases appear as the first two particles in the three-particle cluster of Example (21):

(21) Lei5 m4-sai2 bei2 cin2, Aa3-koeng4 ji5ging1 bei2-zo2 ge3 laa3 wo3. 2SG NEG-need give money Ah-Keung already give-PERF SFP SFP SFP 'You don't need to pay. Ah-Keung already paid.'

These three SFPs can only appear in the order shown here. It is unacceptable for the SFP cluster ge3 laa 3 wo3 to use any of the other five possible linear word orders: *ge3 wo3 laa3; *laa 3 ge3 wo3; *laa 3 wo3 ge3; *wo3 laa 3 ge3; and *wo3 ge3 laa3. When ge 3 is included in an SFP cluster, it always appears first. ${ }^{12}$ Many authors refer to ge3 as a marker of assertion (e.g., Matthews and Yip 2011: 395), but Sybesma and Li (2007: 1744) argue it is "an 'actuality marker,' asserting that the statement to which it is added is highly relevant to the current conversation". I adopt Sybesma and Li's view and place it in FinP as they did. ${ }^{13}$

The next higher SFP in Example (21) is laa3, which is assumed to head DeicP. (The reason for this was explained in Section 1.) Tang (1998) referred to laa 3 as one of the three inner particles, along with lei4 'recent past' and zaa 3 'only', proposing that these three particles are realizations of tense, heading TP.

12 This excludes particles such as timl 'too' and sinl 'first', which both have two versions, one that precedes ge 3 and one that follows it. Some authors have referred to the versions of tim 1 and $\sin 1$ that precede ge3 as SFPs, but most assume that they are adverbs, as shown in the glosses of this example of tim 1 taken from Matthews and Yip (2011: 395), who referred to both tim 1 and $\sin 1$ as "adverbial particles".

Keoi5 lo2-zo2 dai6 jat1 ming4 tim1 ge3 laa3 wo3. 3SG take-PERF number one place too SFP SFP SFP 'And she got first place too, you know.'

13 Actually they placed its onset $g$ - in FinP. Its rime $e$ and tone 3 were assumed to be a default rime and tone, respectively, with no meaning. 
Seeing laa3 as a marker of tense relates to Sybesma and Li's (2007) argument for placing it in DeicP. In agreement with Tang (1998), other authors have also analyzed lei4 as a marker of the past tense (Sybesma 2004), or of the perfective aspect (Yiu 2001). Yiu additionally said that laa3 marks imperfective aspect, which would make it reasonable to assume that these two particles occupy the same syntactic slot, i.e., because they are both markers of tense/aspect. The SFP lei4 is complicated because it has two functions - it marks the past tense when following a VP, and it marks assertion when following an NP (Yiu 2001). An additional complication is that some consider lei4 to be optionally disyllabic lei4(ge3) (e.g., Matthews and Yip 2011), while others (e.g., Yiu 2001) consider lei4ge3 to be a combination of lei4 + ge3. Attentive readers will note that this creates a different order from the ge3 + laa3 shown in Example (21). The sentence in Example (22) is an example of a disyllabic lei4ge 3 used as a marker of assertion, which does not violate the word order of Example (21) according to Matthews and Yip (2011), because the second syllable of lei4ge3 is not the ge 3 that heads FinP, i.e., lei4ge 3 is a disyllabic morpheme.

$\begin{array}{llllll}\text { M4-hai6 } & \text { pou2tung1 } & \text { muk6, hai6 } & \text { hung4-muk6 } & \text { lei4ge3 } & \text { wo3. } \\ \text { not-be } & \text { ordinary } & \text { wood be } & \text { red-wood } & \text { SFP } & \text { SFP }\end{array}$

'Oh, I see it's not ordinary wood but rosewood.'

(Matthews and Yip 2011: 397)

Matthews and Yip assumed that ge3 and lei4ge3 both express assertion and implied that they occupy the same syntactic slot (p. 395). It is not clear if they were including the past tense lei4 (ge3) in their story. I will tentatively hypothesize that because one function of lei4(ge3) is to express past tense, it heads DeicP along with laa3. ${ }^{14}$

The third SFP that Tang (1998) listed as an inner particle is zaa3, and his argument for placing it in $\mathrm{T}^{0}$ is that it has inflectional affix features (p. 52). He lists the inflected forms zaa3, zaa4, zel, and zek1. I instead assume that zaa4 is a contraction of zaa3 plus the question particle aa4 (cf. Kwok 1984: 10; Matthews and Yip 2011: 391), while zel and zekl are assumed to have discourse meanings beyond that of zaa3, which is a focus particle that only means "only" (see Section 5 for a contrast between zaa3 and ze1). The SFPs zel and zek1 are treated as separate SFPs that head DiscourseP. Kwok (1984) cited laa3 + zek1 as a combination found in her corpus. If this is an acceptable combination, then these two particles must occupy separate syntactic slots, contrary to Tang (1998). The SFP zaa3 is widely reported to be a restrictive focus particle, including by Tang (1998), and

14 There are of course potential problems with this hypothesis. First of all, the other function of lei4(ge3) does not seem to be tense related, so placing it in DeicP is problematic. A possible solution would be to assume there are two lei4(ge3) SFPs: a past tense marker that heads DeicP and an assertion marker that heads FinP. If lei4ge 3 is assumed to be lei4 + ge 3 and ge 3 is analyzed as a separate SFP, which is in fact the one that heads FinP, then we could adopt Tang's (1998) original proposal for lei4, which is that it is an overt expression of $\mathrm{T}$, in which case, it appears in the sentence-final position because TP in Cantonese is head-final. 
it is therefore assumed to occupy FocP directly above DeicP (see Lee 2019 for a detailed discussion of zaa3).

The next phrase in the structure is InterP. As argued in Section 2.1, Cantonese has no overt particle that functions to mark a clause as interrogative, and InterP is therefore assumed to be headed by a null particle with the feature [+Inter]. The phrase above InterP is ForceP, and this is also assumed to be headed by null particles that mark the clause type because Cantonese has no overt clause-typing particles.

The two remaining phrases are DiscourseP and AffectP. The vast majority of SFPs are assumed to head DiscourseP, an idea that is roughly comparable to Tang's $(1998,2002)$ and A. Law's $(2002,2004)$ division of SFPs into "inner particles" and "outer particles". In this case, the division is based on whether the particles lie above or below ForceP. What remains are SIPs, most of which can optionally be used in isolation as interjections. These are assumed to head AffectP. An example of one that cannot be used in isolation is the SIP mat1 'what', illustrated below in Example (26). The contrast in meanings between particles that head DiscourseP vs. AffectP is discussed in the following section.

Most of the SFP clusters described in the literature are accounted for by the structure shown in (8) and (20). I follow the general practice of treating SFPs, such as gaa 3 , gaa4, and zaa4, as contractions of ge $3+a a 3$, ge $3+a a 4$, and zaa 3 $+a a 4$, respectively. The orders of each of these fit into the structure in (20); ge3 heads FinP, zaa3 heads FocP, and $a a 3$ and $a a 4$ are assumed to head DiscourseP. The following two examples appear to conflict with the order of phrases in (20), because they show two SFPs that are both assumed to head DiscourseP: zel 'restriction and downplay' followed by maa $3^{15}$ 'obvious/persuasion' in Example (23), and zel followed by bo3 'noteworthiness' in Example (24).

$\begin{array}{clllll}\text { Husband: Lei5 } & \text { m4-hou2 } & \text { zoi3 } & \text { maai5 } & \text { je5 } & \text { laa3. } \\ \text { 2SG } & \text { NEG-good again buy } & \text { thing } & \text { SFP } \\ \text { 'Don't you go buying more stuff.' } & & \end{array}$

Wife: Ngo5 tai2-haa5 ze1 maa3.

1SG look-DEL SFP SFP

'I'm just going to take a look.'

(Matthews and Yip 2011: 396)

(24) Laam4zai2 tek3-bo1 tung4maai4 leoi5zai2 tek3-bo1 mou5 mat1 boy kick-ball and girl kick-ball NEG any fan1bit6 ge3 ze3 bo3. difference SFP SFP SFP

'Boys play ball and girls play ball - there's no difference.'

(Matthews and Yip 2011: 397)

15 This is an abbreviated or contracted form of aalmaa3 'obvious/persuasion' and should not be confused with the question SFP maa3. 
The SFPs ze1 and maa3 in the second sentence of Example (23) are assumed by Matthews and Yip (2011) to be a contraction of ze1 + aalmaa3 'obvious', and the $z e 3$ of (24) used the same Chinese character as zel, so they presumably assumed that its tone had assimilated within this cluster. The problem with Examples (23) and (24) is that ze1, aalmaa3, and bo3 all express meanings that link the sentence to the discourse and are therefore assumed to head DiscourseP. As such, zel should not be able to co-occur with either aalmaa3 or bo3. Leung (2005 [1992]: 87) and Kwok (1984: 62) also gave examples of zel and aalmaa3 used in combination. However, in Kwok's (1984: 10) list of SFP combinations, she showed this to be a contraction of zaa3 + aalmaa3, and I propose that this is actually what is combined in these examples, i.e., the first SFP is zaa3, which heads FocP, rather than ze1, which heads DiscourseP. This two-particle combination is pronounced zaalmaa3, zelmaa3, or zilmaa3. Even if the pronunciation zelmaa3 is used, this can be seen as a change induced by the contraction of the two particles (cf. Sybesma and Li 2007: 1776 on vowel changes in the intermediate position in clusters). The SFP zaa3 contracts with the initial vowel and tone 1 of aalmaa3, resulting in zaal, zel, or zil. The middle SFP ze3 in Example (24) is not a contraction but is merely zaa3 being used in a cluster, which is why it uses its original tone 3 . The vowel change from $a a$ to $e$ is just a phonological phenomenon frequently seen in clusters (Sybesma and Li 2007: 1776). Matthews and Yip (2011) argued that Examples (23) and (24) both express the meaning of downplay, which is apparently why they assumed that the SFP was zel rather than zaa3. I don't agree that Example (24) expresses downplay, and I believe that the meaning of downplay in Example (23) comes pragmatically from being a response to what the husband said - it does not need to be expressed explicitly by an SFP. As such, Examples (23) and (24) are not seen as counterexamples to the structure proposed in (20).

Leung (2005 [1992]) gave this example of what he considered to be a combination of five SFPs:

(25) Lei5 waa6 zeoi3 do1 to1 go3-leng4 jyut6 tim1 ge3 zaa1-maa5.

2SG said most more delay CL-little month too SFP SFP-SFP (tone 5)

'You said it would only be delayed another month more at the most.'

(Leung 2005 [1992]: 87)

This sentence includes another contraction of zaa3 + aalmaa3, shown as zaalmaa5. Leung construed this sentence as containing five SFPs, treating the adverb timl as an SFP, as well as tone 5, which he analyzed as an intonational SFP. He construed this as tim $1+g e 3+z e 1+$ aalmaa $3+$ a low-rise tone shown as 5 . Here, timl is assumed to be an adverb, and zel is assumed to be zaa3 for the reasons stated above - in this case, it is obvious that the speaker is not downplaying the situation. The first four particles in this example are therefore not a problem for the structure in (20), and I am not aware of any other SFP clusters cited in the literature that would pose a problem. Regarding the fifth particle 
(i.e., tone 5), it is beyond the scope of this paper to address the complicated issue of tones that are associated with segmental particles (see Wakefield 2020: Ch. 7 for a discussion of such tones).

Some examples of Cantonese SIPs with very rough English translations are as follows: laa4 'see?'; aaljaa3 'oh no!'; waa3 'wow'; ji2 'huh?'; ce1 'geez'; weil 'hey'; haa2 'huh?'; and mat1 'what' (See Matthews and Yip 2011: 410-412 for some discussion and examples). All of these SIPs - except for mat1 - can be used as interjections in isolation, and when this happens, the associated clause remains unpronounced. ${ }^{16}$ Haegeman (2014: 118, footnote 2) said the following about West Flemish, Dutch, and Italian particles that appear in the highest functional projection, which she referred to as a speaker-oriented SAP, and which is what is referred to here as AffectP:

$[\mathrm{O}]$ nly a [discourse marker (DM)] that can be initial can also constitute an utterance by itself. Final DMs cannot appear in isolation - i.e. as "interjections." The generalisation extends to Dutch and to the Italian dialects analysed by Penello and Chinellato (2008a, 2008b). Anticipating the discussion, the outcome of my analysis is that only DMs that are merged in the higher Speech Act Projection (cf. section 5) can be used as interjections.

Tang (2011) similarly proposed an extra projection above his projection for outer SFPs, arguing that this is where Cantonese interjections lie. Note that Haegeman (2014) said interjections must occupy the higher of her two speechact projections; she did not say that all particles in the higher projection must be interjections. ${ }^{17}$ Cantonese has at least one particle mat1 'what', for instance, that appears sentence-initially, but which cannot be used in isolation as an interjection, and because it can be used in combination with an SFP, it is assumed that mat1 occupies AffectP.

Mat1 ngo5 san1 joeng5-zo2 zek3 gau2
SIP 1SG new raise-PERF CL dog
'What, I have a new dog?! (Actually I don't)'
(Heim et al. 2016: 121)

It appears that no Cantonese particles can be used in both sentence-final and sentence-initial positions. In contrast, Munaro (2010) said that many particles in Northern Veneto can be used in both final and initial positions, and Haegeman (2014) demonstrated that the same is true for some West Flemish particles. She explained that the particle "ze has two uses. With rising intonation it is used to

16 See Munaro (2010: 76-81) for a syntactic proposal of how this might work.

17 As a reminder to readers, what Haegeman (2014) referred to as the higher speaker-oriented speech act phrase $\left(\mathrm{SAP}_{\mathrm{S}}\right)$, I call AffectP, and what she referred to as the lower hearer-oriented speech act $\mathrm{SAP}_{\mathrm{H}}$, I call DiscourseP. 
draw the addressee's attention. With falling intonation, the function of zè has an evidential function and signals that the discourse context provides direct or indirect evidence for the content of the utterance" (p. 123). Her conclusion was that $z e ́$ with rising intonation occupies the higher projection above ForceP, and that $z \grave{e}$ with falling intonation occupies the lower of these two projections (see footnote 17). Depending on whether or not zé attracts the attached clause to its SPEC position, it can either appear sentence-initially, as in Example (27a), or sentence-finally after $z \dot{e}$, as in Example (27b).
a. Zé, k'een gedoan zè.
zé I-have done zè
'I have finished, see.'
b. K'een gedoan zè, zé.

If we accept that the sentence-final zé in Example (27b) is not a separate utterance, i.e., is not being used in isolation as an interjection, then it appears that while Cantonese has no SIPs that attract DiscourseP to raise to the SPEC of AffectP, languages like Northern Veneto and West Flemish do. ${ }^{18}$

\section{The functions and meanings of particles}

Can particles in the speech act domain above ForceP really be divided into only two types? Del Gobbo et al. (2015) concluded as follows:

[T] he pragmatic import of [sentential] particles... [is] in some cases parallel in Mandarin Chinese and Romance. This suggests that also pragmatics obeys some universal constraints and the grammaticalization process of pronouns, verbs and adverbs into (CP or IP) particles select only some pragmatic values among all the a priori possible ones.

This observation does not resolve the issue of how many phrases exist in the left periphery, but if there are universal constraints on the types of particles that appear there, then it is possible that sufficient investigation involving enough languages will result in a clear answer. I tentatively agree with those studies that conclude there are only two phrases in the left periphery above ForceP that fit what have variably been labeled MoodP, DiscourseP, PragmaticP, AttitudeP, and which I have labeled DiscourseP and AffectP. A question that remains is what distinguishes the particles that head one phrase from those that head

18 While Cantonese does not appear to have particles that are optionally sentence-initial or sentencefinal, there are at least two question particles ho2 and haa2 that have been argued to have both SFP and interjection versions. However, the interjection versions never appear sentence-initially; they only appear after a sentence after a short pause, and they always appear in isolation. For details on both of these particles, see Cheung (2007) and Tang (2020). If they do indeed have two versions, then the SFP version is assumed to head DiscourseP and the interjection version to head AffectP. A question that needs to be investigated is whether or not the meanings of the two versions differ, as proposed in Section 5. 
the other. We can also ask what distinguishes the left-periphery particles in these two phrases above ForceP from those that head phrases below it. The answer to these questions can only come from examining particles' functions and meanings and looking for some characteristics that distinguish one group from the other. Different methods have been used to describe the meanings of particles, and the method that I believe can offer the best results is the use of paraphrase, such as has been done for German modal particles (Schubiger 1965), Northern Venetian interjections (Munaro 2010), a Singapore English SFP (Besemeres and Wierzbicka 2003), and Cantonese SFPs (Wakefield 2011, Wakefield 2014, Wakefield 2020). A similar approach commonly found in the literature is to paraphrase particles' meanings at the end of the English translations of example sentences (e.g., Kwok 1984 for Cantonese; Bayer and Obenauer 2011 for German).

Of course, a particle's definition, whatever the method used, is only useful to the extent it is accurate. The goal should be to write an accurate, context-independent definition that includes all and only the meaning of the particle. Bayer and Obenauer (2011: 450) said that discourse particles “express the speaker's attitude about him-/herself or about the hearer with respect to the propositional content of the utterance". Munaro's (2010: 77) definitions of interjections included "the mental state of the speaker" and "a deictic expression, typically a demonstrative, that refers to the entity or event of the external world that is the source of that mental state". In line with both of these views, Wakefield (2020: 76) said "deictic elements whose antecedents are the proposition plus one or more discourse elements must be included in a discourse marker's explication". This method for defining particles uses speaker-oriented definitions that include references to the speaker's beliefs and deictic expressions that refer to the proposition (or a portion thereof) and to one or more elements from the discourse. The question remains as to what distinguishes the meanings of particles in different positions. Wakefield (2020) defined a pair of related SFPs, one member of which lies below ForceP (zaa3) and one that lies above ForceP (ze1). The difference in these two SFPs' definitions offers an example of a contrast between particles that lie on either side of ForceP.

Most authors agree that zaa3 is a restrictive focus particle that means 'only', with no additional connotative meaning. In contrast, zel means 'only' plus a downplay of the event. Consider the sentence in (28) from Fung (2000: 59):

$\begin{array}{lll}\text { Sap6 } & \text { man1 } & \text { zaa3/ze1 } \\ \text { ten } & \text { dollar } & \text { SFP }\end{array}$

'(It's) only ten dollars.'

If this sentence is said in response to the question "How much money do you have?" then it is not very acceptable to use zel, because one would not downplay a small amount of money in response to this question. But if it was said in response to the question "Why are you wasting your money on that?" then zaa3 and zel are 
both acceptable, with zel additionally downplaying any potential harm caused by the event of spending 10 dollars. Wakefield (2020: 168-169) defined these two particles as follows, where $\mathrm{P}$ stands for the proposition:

$$
\mathrm{P}+z a a 3
$$

it is this much/many, (it is) not more

(30) $\mathrm{P}+z e 1$

a. it is this much/many, (it is) not more

b. you are thinking something bad

c. it is not like this

Line (30a), which is the same as (29), only expresses the meaning 'only'. Lines $(30 \mathrm{~b}-\mathrm{c})$ express downplay. The antecedent of "this much/many" is the element within the sentence that is put into restrictive focus. In Example (28), for instance, this element is sap6 man1 "ten dollars'. The antecedent of "something bad" and "this" in lines $(30 \mathrm{~b}-\mathrm{c})$ is some proposition that the speaker perceives to be in the mind of the hearer. And the speaker's perception of this hearer-based belief stems from something in the discourse context.

This is only one example, but it seems reasonable to hypothesize that all particles below ForceP should be definable strictly in reference to sentence-internal information, even though these particles are discourse related. The definition of a topic marker, for instance, would include a deictic element that refers to the sentence's grammatical topic, but it is the semantic content of the topic itself that refers to something from the discourse, not the topic marker. Similarly, a focus marker selects something from within the sentence and brings attention to it, emphasizing it or, as in the case of zaa3, restricting its amount or degree, but the discourse-based reason for this focus is figured out pragmatically - it is not expressed by the focus marker itself. The particle ze1, in contrast, is a focus marker that also expresses downplay with a direct reference to something in the discourse, and this is why it heads DiscourseP. Based on this, the working hypothesis is that particles whose semantics only include deictic elements with sentence-internal antecedents lie below ForceP; particles that refer to antecedents in the discourse lie above ForceP.

There still remains the distinction in functions and meanings of particles that head DiscourseP vs. AffectP. I propose that the most salient distinction here relates to the expression of emotion. Particles that head either phrase can express things such as evidentiality and speaker stance, but only those that head AffectP express speaker emotions. Support for this idea comes from authors' descriptions of interjections. When Munaro (2010: 77) said that an interjection expresses "the mental state of the speaker", he was referring to things such as "surprise, curiosity, desire, disappointment, anger and so on", rather than to speaker stance. Goddard (2014: 54) said that there are emotive interjections that express emotions and cognitive interjections that express the speaker's information state; but he went 
on to say that cognitive interjections have "an overlap with the emotive category because these interjections arguably also convey an element of feeling". I believe that interjections can be seen as the interface between language and the nonlinguistic expression of emotion, which is a form of animal communication. They are clearly linguistic because they differ in form and meaning from one language to the next (Wierzbicka 1992), and they can combine syntactically with a sentence. However, their propositional content is related to emotions (cf. Munaro 2010: 77), and they are regularly used with nonlinguistic forms of prosody and gestures, indicating that they have a close connection to the expression of emotion.

Some proposed definitions of Italian interjections are shown here in Example (31) and some definitions of Cantonese interjections are shown in Example (32).

(31) a. Toh!

I inform you that this fact arouses in me a slight feeling of surprise

b. Eh!

I ask you to pay attention to me about this

c. Magari!

I express the wish that this could happen

d. Beh?

I ask you to explain to me why you said/did this

(Munaro 2010: 77)

(32) a. Waa3!

I now know something about something

I didn't know before that it can be like this

I feel something because of this

b. Ailjaa3!

I think like this: "something is happening"

I didn't think before that it will be like this

I don't want it to be like this

I feel something bad because of this

(Goddard 2014: 58)

Note that Munaro's (2010) definition of Toh, and both of Goddard's (2014) definitions, include the word "feel(ing)". Goddard's definitions are especially noteworthy because his study was specifically and entirely about defining interjections, and he used a method for defining words that has been developed over a period of more than 30 years based on the theory of the natural semantic metalanguage (for details, see Wierzbicka 1996; Goddard 2011). Each of Goddard's (2014) definitions of English and Polish interjections also included the word "feel". Based on the assumption that his definitions are on the right track, I hypothesize that particles that head AffectP express feelings and are less explicitly connected to the propositional content of the sentence, which is why many of them can appear as interjections in isolation. 


\section{Concluding remarks}

This paper proposed a structure for the left periphery of Cantonese, shown in (8) and (20). This structure is a slight modification of the structures that have been proposed in the literature based on evidence from a number of languages, including Cantonese. It was argued that this structure is able to account for all of the syntactic ordering of Cantonese SFP clusters, as well as for all of the particles' functions and meanings. The conclusions are based on the following assumptions:

- SFPs are not clause-typers;

- $[+\mathrm{Q}]$ SFPs in Cantonese do not have the feature [+Inter];

- The only [+Inter] SFP in Cantonese is null and is associated with A-not-A constructions - it either moves up in LF from a phrase attached to VP or is base generated in InterP and undergoes long-distance Agree with the [+Inter] feature that is attached to VP;

- All particles above ForceP can be distinguished from those between ForceP and TP based on their meanings: those below ForceP do not have deictic elements that refer directly to the discourse, while those above ForceP do;

- Particles that head the lower of the two phrases above ForceP have different meanings from those that head the higher phrase: particles heading either phrase include deictic elements that refer to speaker stance and to antecedents in the discourse, but only those in the higher phrase are defined in terms of human emotion.

- Only main clauses include particles with deictic elements that refer to antecedents in the discourse. Therefore, the two functional phrases above ForceP only project in main clauses (see footnote 11).

Further empirical evidence on the syntax and semantics of left-periphery particles in a variety of languages will determine the extent to which these assumptions are justified.

\section{Acknowledgments}

I am grateful to the anonymous reviewers for their helpful and insightful comments, as well as to those who commented on an earlier version of this paper that was presented in June 2019 at the $1^{\text {st }}$ International Workshop on Cantonese Syntax at Palacký University, Olomouc, Czech Republic. The research described here was supported by the European Regional Development Fund Project 'Sinophone Borderlands - Interaction at the Edges' (CZ.02.1.01/0.0/0.0/16_019/0000791).

\section{References}

Aboh, Enoch O. \& Roland Pfau. 2010. What's a Wh-word go to do with it? In Paola Benincà \& Nicola Munaro (eds.), Mapping the left periphery, 91-124. New York: Oxford University Press.

Allan, Keith. 2006. Clause-type, primary illocution, and mood-like operators in English. Language Sciences 28(1). 1-50. 
Arndt, Walter. 1960. "Modal particles" in Russian and German. Word 16. 323-336.

Bailey, Laura R. 2010. Sentential word order and the syntax of question particles. Newcasltle Working Papers in Linguistics 16. 23-43.

Bayer, Josef \& Hans-Georg Obenauer. 2011. Discourse particles, clause structure, and question types. The Linguistic Review 28. 449-491.

Besemeres, Mary \& Anna Wierzbicka. 2003. The meaning of the particle lah in Singapore English. Pragmatics \& Cognition 11(1). 3-38.

Cheung, H. Samuel. 2007. Xianggang Yueyu yufa de yanjiu [A grammar of Cantonese as spoken in Hong Kong], revised edn. Hong Kong: The Chinese University Press.

Chor, Winnie Oi-Wan, Foong Ha Yap \& Tak-Sum Wong. 2016. Chinese interrogative particles as talk coordinators at the right periphery: A discourse-pragmatic perspective. Journal of Historical Pragmatics 17(2). 178-207.

Del Gobbo, Francesca, Nicola Munaro \& Cecilia Poletto. 2015. On sentential particles: A crosslinguistic study. In Sylvie Hancil, Alexander Haselow \& Margje Post (eds.), Final particles, 360-386. Berlin: De Gruyter Mouton.

Fung, Roxana Suk-yee. 2000. Final particles in Standard Cantonese: Semantic extension and pragmatic inference. Columbus, $\mathrm{OH}$ : The Ohio State University dissertation.

Goddard, Cliff. 2011. Semantic analysis: A practical introduction, 2nd edn. New York: Oxford University Press.

Goddard, Cliff. 2014. Interjections and emotion (with special reference to "Surprise" and "Disgust"). Emotion Review 6(1). 53-63.

Gunlogson, Christine. 2003. True to form: Rising and falling declaratives as questions in English. New York \& London: Routledge.

Haegeman, Liliane \& Virginia Hill. 2013. The syntactization of discourse. In Raffaella Folli, Christina Sevdali \& Robert Truswell (eds.), Syntax and its limits, 370-390. New York: Oxford University Press.

Haegeman, Liliane. 1997. Elements of grammar. In Liliane Haegeman (ed.), Elements of grammar: Handbook in generative syntax, 1-71. Dordrecht: Kluwer Academic Publishers.

Haegeman, Liliane. 2014. West Flemish verb-based discourse markers and the articulation of the speech act layer. Studia Linguistica 68(1). 116-139.

Heim, Johannes, Hermann Keupdjio, Zoe Wai-Man Lam, Adriana Osa-Gómez, Sonja Thoma \& Martina Wiltschko. 2016. Intonation and particles as speech act modifiers: A syntactic analysis. Studies in Chinese Linguistics 37(2). 109-129.

Hirst, Daniel. 1983. Interpreting intonation: A modular approach. Journal of Semantics 2(2). 171-182.

Huang, C.-T. James, Y.-H. Audrey Li \& Yafei Li. 2009. The syntax of Chinese. New York: Cambridge University Press.

Iida, Maki. 2017. Yueyu jumo zhuci ge2 de yuyi he yufahua tujing [The meaning and grammaticalization path of the sentence-final particle ge2 in Cantonese]. Zhongguo Yuwen [Studies of the Chinese language] 4. 421-437, 511. 
Kuong, Io-Kei Joaquim. 2008. Yes/no questions particles revisited: The grammatical functions of mo4, me1, and maa3. In Marjorie K.M. Chan \& Hana Kang (eds.), Proceedings of the 20th North American Conference on Chinese Linguistics (NACCL-20), vol. 2, 715-733. Columbus, Ohio: The Ohio State University.

Kwok, Helen. 1984. Sentence particles in Cantonese. Hong Kong: Centre of Asian Studies, University of Hong Kong.

Law, Ann. 2002. Cantonese sentence-final particles and the CP domain. UCL Working Papers in Linguistics 14. 375-398.

Law, Ann. 2004. Sentence-final focus particles in Cantonese. London: University College London dissertation.

Law, Paul. 2006. Adverbs in A-not-A questions in Mandarin Chinese. Journal of East Asian Linguistics 15(2). 97-136.

Law, Sam-Po. 1990. The syntax and phonology of Cantonese sentence-final particles. Boston, MA: Boston University dissertation.

Lee, Peppina Po-lun. 2019. Focus manifestation in Mandarin Chinese and Cantonese: A comparative perspective. Oxon \& New York: Routledge.

Leung, Chung-sum. 2005 [1992]. Dangdai Xianggang Yueyu yuzhuci de yanjiu [A study of the utterance particles in Cantonese as spoken in Hong Kong]. Hong Kong: Language Information Sciences Research Centre, City University of Hong Kong.

Li, Boya. 2006. Chinese final particles and the syntax of the periphery. Leiden: Leiden University dissertation.

Li, Charles N. \& Sandra A. Thompson. 1981. Mandarin Chinese: A functional reference grammar. London: University of California Press.

Matthews, Stephen \& Virginia Yip. 2011. Cantonese: A comprehensive grammar, 2nd edn. New York: Routledge.

Munaro, Nicola. 2010. On the edge-feature of particles, interjections, and short answers. In Anna Maria Di Sciullo \& Virginia Hill (eds.), Edges, heads, and projections, 67-86. Amsterdam: John Benjamins Publishing Company.

Munaro, Nicola \& Jean-Yves Pollock. 2005. Qu'est-ce-que (qu)-est-ce-que? A case study in comparative Romance interrogative syntax. In Guglielmo Cinque \& Richard S. Kayne (eds.), The Oxford handbook of comparative syntax, 542-606. New York: Oxford University Press.

Obenauer, Hans-Georg. 2006. Special interrogatives - Left periphery, Wh-doubling, and (apparently) optional elements. In Jenny Doetjes \& Paz González (eds.), Romance languages and linguistic theory 2004: Selected papers from 'Going Romance', Leiden, 9-11 December 2004, 247-273. Amsterdam: John Benjamins Publishing Company.

Paul, Waltraud. 2014. Why particles area not particular: Sentence-final particles in Chinese as heads of split CP. Studia Linguistica 68(1). 77-115.

Poletto, Cecilia \& Jean-Yves Pollock. 2000. On the left periphery of some Romance wh-questions. University of Venice Working Papers in Linguistics 10(2). $115-182$. 
Rizzi, Luigi. 1997. The fine structure of the left periphery. In Liliane Haegeman (ed.), Elements of grammar: Handbook in generative syntax, 281-337. Dordrecht: Kluwer Academic Publishers.

Rizzi, Luigi. 2001. On the position of Int(errogative) in the left periphery of the clause. In Guglielmo Cinque \& Giampaolo Salvi (eds.), Current studies in Italian syntax: Essays offered to Lorenzo Renzi, 287-296. Leiden: Brill.

Schubiger, Maria. 1965. English intonation and German modal particles: A comparative study. Phonetica 12(2). 65-84.

Simpson, Andrew. 2014. Sentence-final Particles. In C.-T. James Huang, Y. -H. Audrey Li \& Andrew Simpson (eds.), The handbook of Chinese linguistics, 156-179. West Sussex: Wiley-Blackwell.

Smith, Carlota S. 2007. Reference time without tense. In Louis de Saussure, Jacques Moeschler \& Genoveva Puskás (eds.), Recent advances in the syntax and semantics of tense, aspect and modality, 229-250. Berlin: Mouton de Gruyter.

Speas, Margaret. 2004. Evidentiality, logophoricity and the syntactic representation of pragmatic features. Lingua 114(3). 255-276.

Speas, Peggy \& Carole Tenny. 2003. Configurational properties of point of view roles. In Anna Maria Di Sciullo (ed.), Asymmetry in grammar, vol. 1, Syntax and semantics, 315-344. Amsterdam: John Benjamins Publishing Company.

Sybesma, Rint \& Boya Li. 2007. The dissection and structural mapping of Cantonese sentence final particles. Lingua 117(10). 1739-1783.

Sybesma, Rint. 2004. Exploring Cantonese tense. Linguistics in the Netherlands 2004 21. 169-180.

Tang, Sze-Wing. 1998. Parametrization of features in syntax. Irvine, CA: University of California, Irvine dissertation.

Tang, Sze-Wing. 2002. Yueyu jumo zhuci de buduicheng fenbu [Asymmetric distribution of Cantonese sentence final particles]. Zhongguo Yuwen Yanjiu [Studies in Chinese linguistics] 2(14). 75-84.

Tang, Sze-Wing. 2006. Yueyu yiwenju "xian" de jufa tedian [Syntactic properties of sin in Cantonese interrogatives]. Zhongguo Yuwen [Studies of the Chinese language] 312(3). 225-232.

Tang, Sze-Wing. 2010. Hanyu julei he yuqi de jufa fenxi [A syntactic analysis of clause types and mood in Chinese]. Hanyu Xuebao [Chinese linguistics] 29(1). 59-63.

Tang, Sze-Wing. 2011. Cartographic syntax of interjections in Cantonese. Paper presented at the Fifth International Conference on Formal Linguistics (ICFL-5), Guangdong University of Foreign Studies, 10-12 December.

Tang, Sze-Wing. 2015. Cartographic syntax of pragmatic projections. In Audrey Li, Andrew Simpson \& Wei-Tien Dylan Tsai (eds.), Chinese syntax in a crosslinguistic perspective, 429-441. New York: Oxford University Press.

Tang, Sze-Wing. 2020. Cartographic syntax of performative projections: Evidence from Cantonese. Journal of East Asian Linguistics 29. 1-30.

Wakefield, John C. 2011. Disentangling the meanings of two Cantonese evidential particles. Chinese Language \& Discourse 2(2). 250-293. 
Wakefield, John C. 2014. The forms and meanings of English rising declaratives: Insights from Cantonese. Journal of Chinese Linguistics 42(1). 109-149.

Wakefield, John C. 2020. Intonational morphology. Singapore: Springer.

Wierzbicka, Anna. 1992. The semantics of interjection. Journal of Pragmatics 18. 159-192.

Wierzbicka, Anna. 1996. Semantics: Primes and universals. Oxford: Oxford University Press.

Yiu, Carine Yuk-man. 2001. Cantonese final particles "LEI", "ZYU” and "LAA": An aspectual study. Hong Kong: The Hong Kong University of Science and Technology Mphil thesis.

John C. Wakefield

Mailing address: Department of English Language and Literature, Faculty of Arts, Hong Kong Baptist University, Kowloon Tong, Kowloon, Hong Kong

Email: johncw@hkbu.edu.hk

Received: January 22, 2020

Accepted: $\quad$ November 3, 2020 


\title{
畧語左緣助詞的句法和意義
}

\author{
莊域飛 \\ 香港浸會大學、帕拉茨基大學
}

\section{提要}

本文用製圖方法提出在 TP 上面的粵語左緣助詞的句法位置, 包括句末助詞和能單 用為嘆詞的句首助詞。本文修改 Rizzi's (2001) Split-CP 結構。首先把粵語的兩個時 態助詞 (啦和嚟 [嘅]) 置於 FinP 之上的指示詞短語 (DeicP)。然後, 在 ForceP 上面 加兩個功能短語, 句首助詞置於在上的情感詞短語 (AffectP), 而大部分句末助詞置 於在下的話語短語 (DiscourceP)。根據這個提案, 粵語左緣助詞的句法與其他語言 左緣助詞的句法分析, 更為接近。按照功能和意義, 左緣助詞可分為三類：1) 位於 ForceP 跟 TP 之間的助詞不直接表示話語, 2) 位於 DiscourseP 的助詞直接表示話語, 3) 位於 AffectP 的助詞表示人類情感。

\section{關鍵詞}

粵語, 話語助詞, 左緣助詞, 句法 